\title{
Seasonal cycles of Antarctic surface energy balance from automatic weather stations
}

\section{Michiel VAN DEN BROEKE, Carleen REIJMER, Dirk VAN AS, Roderik VAN DE WAL, J. OERLEMANS}

\author{
Institute for Marine and Atmospheric Research Utrecht, PO Box 80005, Utrecht University, Princetonplein 5, \\ 3508 TA Utrecht, The Netherlands \\ E-mail: broeke@phys.uu.nl
}

\begin{abstract}
We present the seasonal cycle of the Antarctic surface energy balance (SEB) using 4 years (1998-2001) of automatic weather station (AWS) data. The four AWSs are situated on an ice shelf, in the coastal and inland katabatic wind zone and the interior plateau of Dronning Maud Land. To calculate surface temperature we use a SEB closure assumption for a surface skin layer. Modelled and observed surface have a root-mean-square difference of $1.8 \mathrm{~K}$ at the plateau AWS (corresponding to an

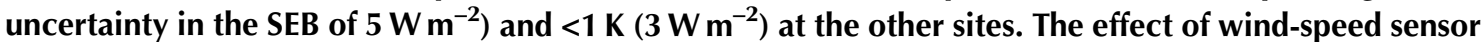
freezing on the calculated SEB is discussed. At all sites the annual mean net radiation is negative and the near-surface air is on average stably stratified. Differences in the seasonal cycle of the SEB are mainly caused by the different wind climates at the AWS sites. In the katabatic wind zone, a combination of clear skies and strong winds forces a large wintertime turbulent transport of sensible heat towards the surface, which in turn enhances the longwave radiative heat loss. On the coastal ice shelf and on the plateau, strong winds are associated with overcast conditions, limiting the radiative heat loss and sensible heat exchange. During the short Antarctic summer, the net radiation becomes slightly positive at all sites. Away from the cold interior, the main compensating heat loss at the surface is sublimation. In the interior, summer temperatures are too low to allow significant sublimation to occur; here, surface heat loss is mainly due to convection.
\end{abstract}

\section{INTRODUCTION}

The surface energy balance (SEB) of a snow surface can be written as:

$$
\begin{aligned}
M & =\mathrm{SHW} \downarrow+\mathrm{SHW} \uparrow+\mathrm{LW} \downarrow+\mathrm{LW} \uparrow+\mathrm{SHF}+\mathrm{LHF}+G \\
& =\mathrm{SHW}_{\text {net }}+\mathrm{LW}_{\text {net }}+\mathrm{SHF}+\mathrm{LHF}+G \\
& =R_{\text {net }}+\mathrm{SHF}+\mathrm{LHF}+G,
\end{aligned}
$$

where $M$ is melt energy $(M=0$ if the surface temperature $\left.T_{\mathrm{s}}<273.15 \mathrm{~K}\right), \mathrm{SHW} \downarrow$ and $\mathrm{SHW} \uparrow$ are incoming and reflected shortwave radiation fluxes, $\mathrm{LW} \downarrow$ and $\mathrm{LW} \uparrow$ are incoming and emitted longwave radiation fluxes, SHF and LHF are the turbulent fluxes of sensible and latent heat and $G$ is the subsurface conductive heat flux. All terms are evaluated at the surface and are defined positive when directed towards the surface.

The atmosphere over Antarctica is cold and lacking water vapour, which limits the amount of downward longwave radiation. At the same time, the ice sheet has a highly reflective snow surface that limits the absorption of shortwave radiation but effectively loses heat in the form of longwave radiation by radiating nearly as a black body. To make up for the surface radiative heat loss, sensible heat is extracted from the lower atmosphere. Summer sublimation is another important aspect of the Antarctic SEB, because it directly influences the mass budget of the ice sheet.

Due to the very cold winter conditions, most experiments dedicated to measuring the Antarctic SEB have been summer-only (Wendler and others, 1988; Heinemann and Rose, 1990; Bintanja and Van den Broeke, 1995; Bintanja, 2000; Van As and others, 2005). Only a few experiments cover the entire annual cycle (Liljequist, 1957; Carroll, 1982; Ohata and others, 1985; King and others, 1996).
These are usually held close to manned stations for reasons of power supply and sensor maintenance. Unfortunately, the network of manned meteorological stations in Antarctica is sparse and heavily biased towards the coast, where micrometeorological conditions are very different from the interior plateau and the katabatic wind zone.

Automatic weather stations (AWSs) may partly remedy the poor data coverage in Antarctica. Similarity theory may be used to calculate sublimation from AWS data (Clow and others, 1988; Stearns and Weidner, 1993; Van den Broeke and others, 2004a). In combination with radiation measurements and a routine that treats heat conduction into the snow, the full annual cycle of individual SEB components may be calculated from AWS data (Bintanja and others, 1997; Reijmer and Oerlemans, 2002; Renfrew and Anderson, 2002).

In this paper, we present seasonal cycles of Antarctic SEB from four AWSs in Dronning Maud Land (Fig. 1). This paper expands on Reijmer and Oerlemans (2002) by using more extensive data treatment methods and longer time series. We focus the discussion on the SEB components in their connection to the local climate and their mutual dependence, building on papers where individual SEB components are discussed in more detail (Van den Broeke and others, 2004b, 2005).

\section{METHODS}

\subsection{AWS description and sensor specifications}

The four AWSs used in this study are situated along a traverse line connecting the coastal ice shelf (AWS 4) to the polar plateau (AWS 9) via the coastal/inland katabatic wind zone 


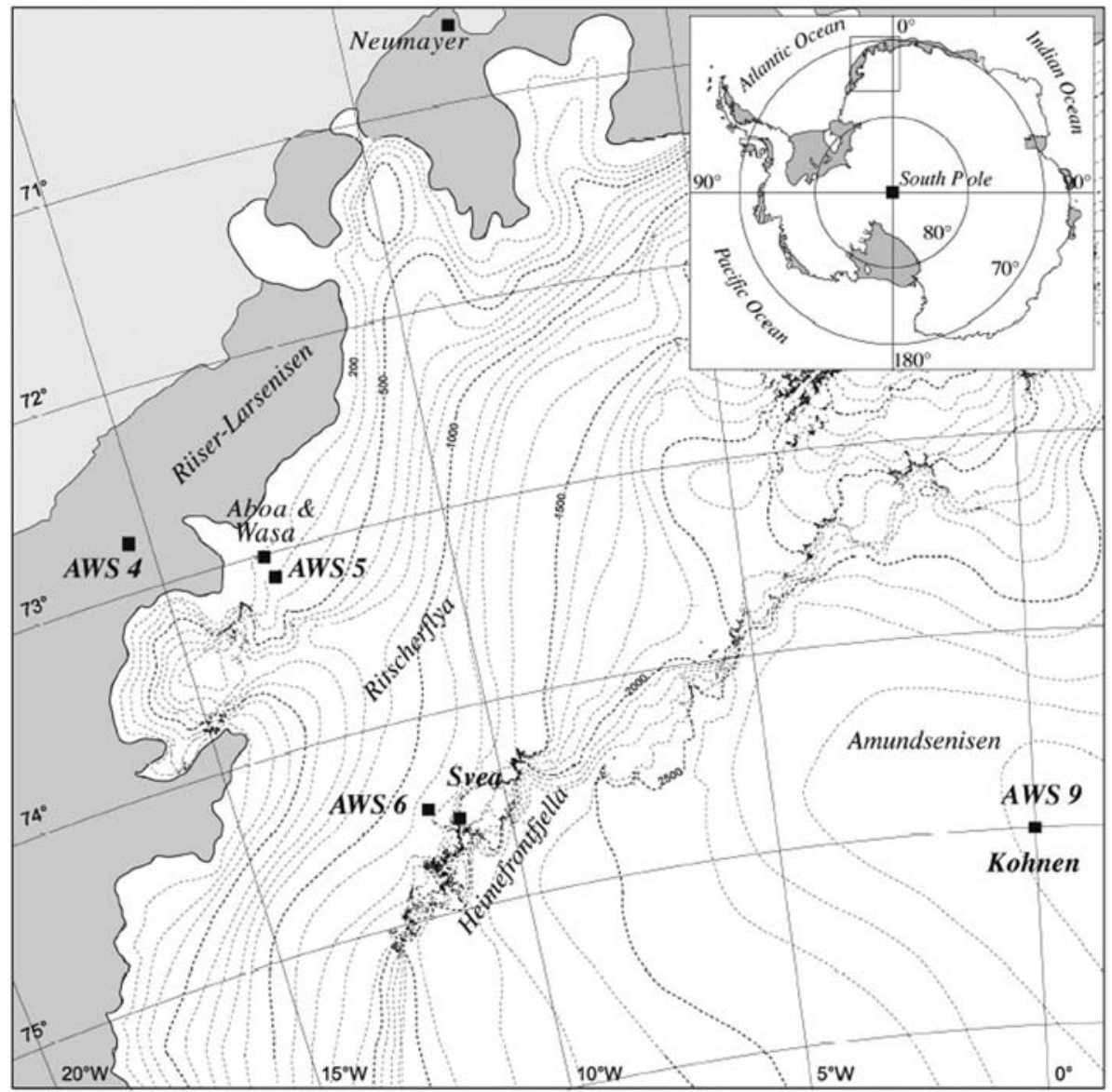

Fig. 1. Map of west Dronning Maud Land, Antarctica, with AWS and station locations (filled squares), main topographical features, ice shelves (grey) and height contours (dashed lines, equidistance $100 \mathrm{~m}$ ).

(AWSs 5 and 6) in Dronning Maud Land, East Antarctica (Fig. 1). AWS 4 is located on the flat Riiser-Larsen Ice Shelf some $80 \mathrm{~km}$ away from the ice-shelf front and $40 \mathrm{~km}$ from the ice-sheet grounding line. This station was removed in January 2002. AWS 5 is located just inland of the grounding line, on the relatively steep coastal slopes of the ice sheet. AWS 6 is situated at the foot of the Heimefrontfjella, also in a region with a relatively large surface slope. AWS 9 is situated on the interior plateau close to Kohnen base, where the surface is relatively flat. Within a radius of at least several $\mathrm{km}$, the surroundings of the AWSs consist of an undisturbed snow surface.

All four AWSs are similar in design; a picture of AWS 9 is shown in Figure 2, and sensor specifications are given in
Table 1. Single-level measurements of wind, temperature and relative humidity are performed at $2.5-3 \mathrm{~m}$ height at the date of installation. Air pressure is measured in the electronics enclosure, which is buried in the snow. A Kipp and Zonen (K\&Z) CNR1 net radiometer measures SHW $\downarrow$, $\mathrm{SHW} \uparrow, \mathrm{LW} \downarrow$ and $\mathrm{LW} \uparrow$. Snow temperatures are measured at initial depths of $0.05,0.1,0.2,0.4,0.8,2,4,6,10$ and $15 \mathrm{~m}$. This depth, as well as the height of the instruments, changes continuously as snow accumulates or is ablated from the surface; these height/depth changes are monitored with a sonic height ranger. The sampling frequency for pressure is 30 min (instantaneous value); all other sensors are sampled at 6 min intervals (instantaneous, except for wind speed, cumulative) after which 2 hour averages are calculated and

Table 1. AWS sensor specifications. EADT: estimated accuracy for daily totals

\begin{tabular}{|c|c|c|c|}
\hline Sensor & Type & Range & Accuracy \\
\hline Air pressure & Vaisala PTB101B & $600-1060 \mathrm{hPa}$ & $4 \mathrm{hPa}$ \\
\hline Air temperature & Vaisala HMP35AC & -80 to $+56^{\circ} \mathrm{C}$ & $0.3^{\circ} \mathrm{C}$ \\
\hline Relative humidity & Vaisala HMP35AC & $0-100 \%$ & $\begin{array}{l}2 \%(\mathrm{RH}<90 \%) \\
3 \%(\mathrm{RH}>90 \%)\end{array}$ \\
\hline Wind speed & Young 05103 & $0-60 \mathrm{~m} \mathrm{~s}^{-1}$ & $0.3 \mathrm{~m} \mathrm{~s}^{-1}$ \\
\hline Pyranometer & Kipp and Zonen CM3 & $305-2800 \mathrm{~nm}$ & EADT $\pm 10 \%$ \\
\hline Pyrradiometer & Kipp and Zonen CG3 & $5000-50000 \mathrm{~nm}$ & EADT $\pm 10 \%$ \\
\hline Snow height & Campbell SR50 & $0.5-10 \mathrm{~m}$ & $0.01 \mathrm{~m}$ or $0.4 \%$ \\
\hline
\end{tabular}


stored in a Campbell CR10 datalogger with separate memory module. Some basic information on AWS location and climate is given in Table 2 .

\subsection{Data treatment}

Due to the harsh climate conditions and the absence of servicing personnel, data from Antarctic AWSs suffer from potentially large errors. The main problems are a limited power supply (preventing the heating and/or ventilation of sensors), low temperatures (deteriorating sensor performance through icing/riming and reducing battery output), year-round low sun angle (degrading the measurement of direct incoming shortwave radiation by instruments with a less than perfect cosine response) and a high surface albedo (increasing the relative error in net shortwave radiation). Recently, many of these problems have been adequately addressed with improved designs for sensor housing and data treatment methods. Most of the methods applied to our AWS data have been described in Van den Broeke (2004a, 2005), and are briefly repeated below.

\section{Temperature $(T)$}

Energy considerations do not allow aspiration of the AWS temperature sensors, which might lead to spuriously high $T$ readings on sunny days with low wind speeds. However, on-site comparisons with ventilated instruments at AWS 6 (Bintanja, 2000) and AWS 9 (Van As and others, 2005) show that, owing to improved radiation shields, the radiation error does not exceed the instrument uncertainty listed in Table 1.

\section{Relative humidity $(\mathrm{RH})$}

The Vaisala HMP35AC instrument incorporates the Humi$\operatorname{cap}^{\mathbb{R}}$, a capacitive device that is calibrated in the factory to measure $\mathrm{RH}$ with respect to water $\left(\mathrm{RH}_{\mathrm{w}}\right)$. Furthermore, a clear cut-off at values well below $100 \%$ is observed

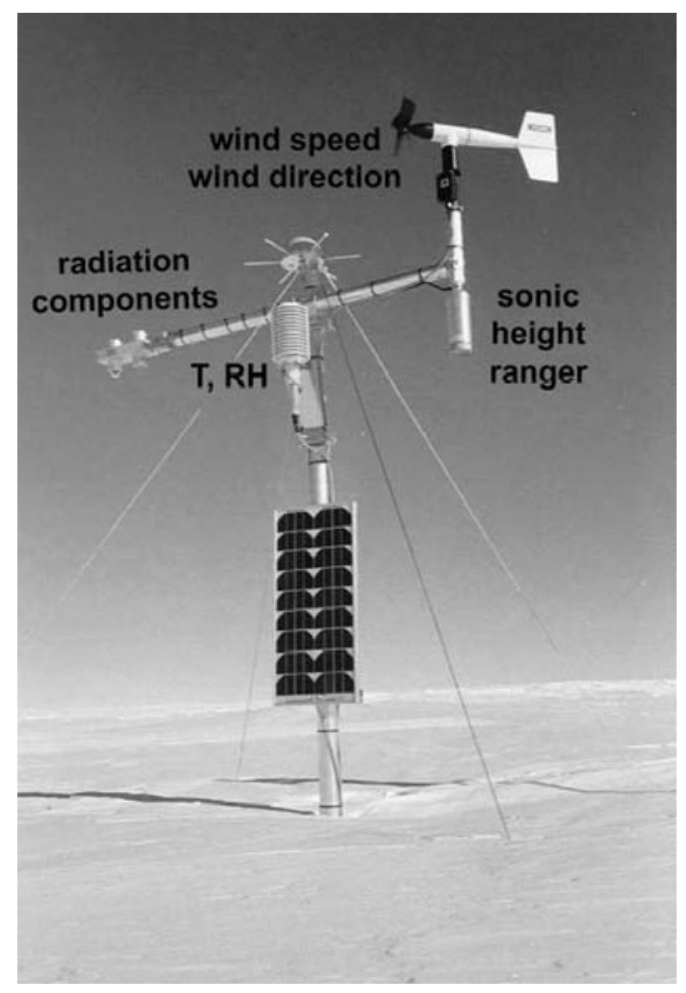

Fig. 2. Picture of AWS 9, taken 4 years after installation, i.e. after approximately $1 \mathrm{~m}$ of snow accumulation. The datalogger and pressure sensor are buried in the snow. The other AWSs have similar designs. $T$ is temperature, $\mathrm{RH}$ is relative humidity.

at temperatures outside the calibration range of the factory $\left(<-20^{\circ} \mathrm{C}\right)$. To remedy this, a two-step correction to the $\mathrm{RH}$ data was applied along the lines of Anderson (1994). On-site comparison at the sites of AWSs 6 and 9 shows that $<5 \%$ difference remains between (corrected) unventilated and ventilated $\mathrm{RH}$ measurements.

Table 2. AWS topographic, climate and SEB characteristics, 1998-2001. If no measurement height is specified, the mean value at AWS sensor level is used

\begin{tabular}{|c|c|c|c|c|}
\hline & AWS 4 & AWS 5 & AWS 6 & AWS 9 \\
\hline Latitude & $72^{\circ} 45.2^{\prime} \mathrm{S}$ & $73^{\circ} 06.3^{\prime} \mathrm{S}$ & $74^{\circ} 28.9^{\prime} \mathrm{S}$ & $75^{\circ} 00.2^{\prime} \mathrm{S}$ \\
\hline Longitude & $15^{\circ} 29.9^{\prime} \mathrm{W}$ & $13^{\circ} 09.9^{\prime} \mathrm{W}$ & $11^{\circ} 31.0^{\prime} \mathrm{W}$ & $0^{\circ} 00.4^{\prime} \mathrm{E}$ \\
\hline Elevation (ma.s.l.) & 34 & 363 & 1160 & 2892 \\
\hline Surface slope $\left(\mathrm{m} \mathrm{km}^{-1}\right)$ & $<1$ & 13.5 & 15 & 1.3 \\
\hline Start of observation & 22 Dec 1997 & 3 Feb 1998 & 14 Jan 1998 & 1 Jan 1998 \\
\hline \multicolumn{5}{|c|}{ Basic climate variables, annual mean } \\
\hline Pressure $(\mathrm{hPa})$ & 979 & 941 & 854 & 673 \\
\hline Temperature $(\mathrm{K})$ & 254.3 & 256.8 & 252.6 & 230.0 \\
\hline Relative humidity (\%) & 93 & 83 & 78 & 93 \\
\hline Specific humidity $\left(\mathrm{g} \mathrm{kg}^{-1}\right)$ & 1.03 & 1.01 & 0.72 & 0.17 \\
\hline $10 \mathrm{~m}$ wind speed $\left(\mathrm{m} \mathrm{s}^{-1}\right)$ & 5.7 & 7.8 & 7.7 & 4.8 \\
\hline Surface albedo & 0.88 & 0.84 & 0.84 & 0.85 \\
\hline \multicolumn{5}{|l|}{ SEB variables, annual mean } \\
\hline$R_{\text {net }}\left(\mathrm{W} \mathrm{m}^{-2}\right)$ & -6.5 & -16.3 & -22.2 & -7.5 \\
\hline $\operatorname{SHF}\left(\mathrm{W} \mathrm{m}^{-2}\right)$ & 7.2 & 18.8 & 24.2 & 7.6 \\
\hline $\operatorname{LHF}\left(\mathrm{W} \mathrm{m}^{-2}\right)$ & -1.1 & -2.8 & -2.3 & -0.2 \\
\hline$G\left(\mathrm{~W} \mathrm{~m}^{-2}\right)$ & 0.3 & 0.3 & 0.1 & 0.1 \\
\hline$M\left(\mathrm{~W} \mathrm{~m}^{-2}\right)$ & 0.2 & 0.1 & 0.0 & 0.0 \\
\hline
\end{tabular}


a

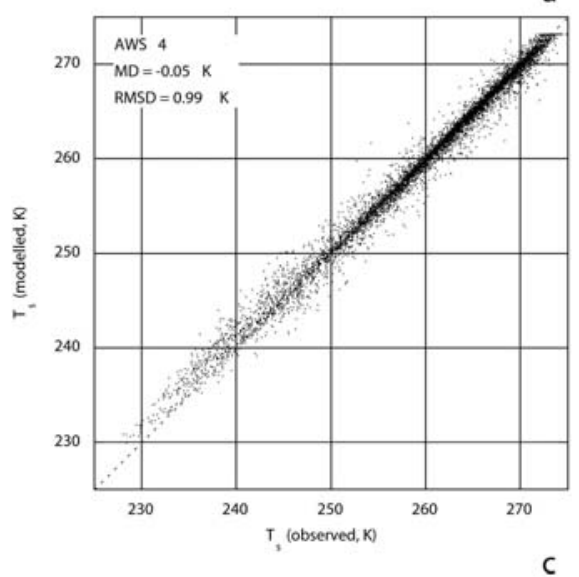

C

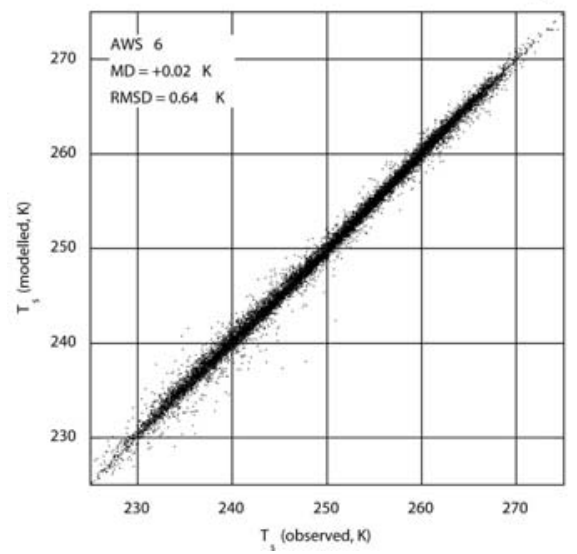

b

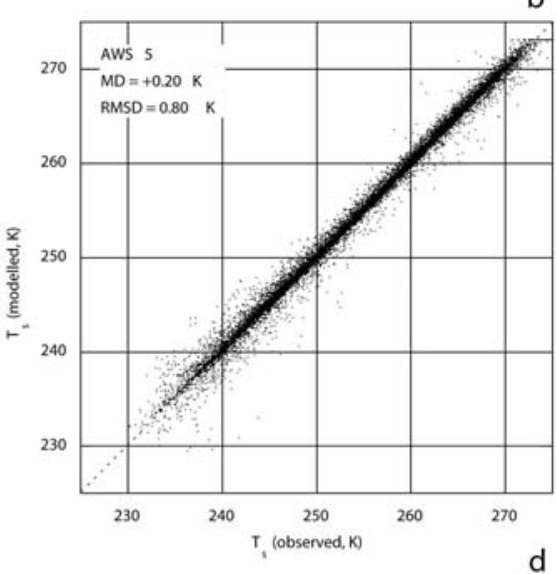

d

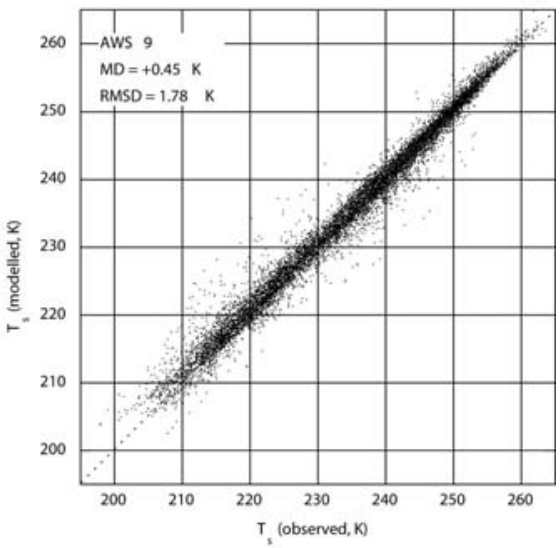

Fig. 3. Modelled vs observed surface temperature (2 hour averages, 1998-2001). MD is mean difference, RMSD is root-mean-square difference. Periods with riming problems at AWSs 4 and 9 were excluded from the comparison since no reliable measured surface temperature is available.

Net shortwave radiation ( $\mathrm{SHW}_{\text {net }}$ )

The K\&Z CNR1 (Fig. 2) houses two K\&Z CM3 pyranometers for downward and upward broadband shortwave radiation flux (spectral range 305-2800 nm). The CM3 has ISO 9060 second-class specifications, which indicates an estimated accuracy for daily shortwave radiation totals of $\pm 10 \%$, but in three on-site tests Van den Broeke and others (2004a) found better than 3\% accuracy for daily mean shortwave fluxes. We used the 'accumulated albedo' method described in that paper to obtain 3\% accuracy also for $\mathrm{SHW}_{\text {net }}$.

\section{Net longwave radiation $\left(\mathrm{LW}_{\text {net }}\right)$}

The K\&Z CNR1 houses two K\&Z CG3 pyrgeometers for downward and upward broadband longwave radiation flux (spectral range $5-50 \mu \mathrm{m}$ ). The factory-provided accuracy of the K\&Z CG3 for daily totals is $\pm 10 \%$, but Van den Broeke and others (2004a) found an accuracy of $1-6 \%$. A serious problem is that wintertime riming of the K\&Z CG3 window causes a large systematic offset in $\mathrm{LW}_{\text {net }}$ at the ice-shelf (AWS 4) and plateau (AWS 9) sites. The only way to remedy this is to replace these measurements with parameterized values, using AWS temperature as the predicting variable. This removes the systematic offset in $\mathrm{LW}_{\text {net }}$ but introduces a random error in daily mean values of $15 \%$ (AWS 4) and 10\% (AWS 9).

\subsection{Energy-balance model}

Equation (1) describes the SEB of a 'skin' layer without heat capacity, the temperature of which reacts instantaneously to a change in energy input. By assuming Equation (1) to be valid, we neglect the effect of snowdrift sublimation, precipitation adding/removing surface heat, and penetration of shortwave radiation in the snow. The latter assumption is justified for fine-grained, dry Antarctic snow (Brandt and Warren, 1993). Given the good agreement between modelled and observed temperature (see next section), the other assumptions are also likely to be valid.

To solve Equation (1), three radiation components (SHW $\downarrow, \mathrm{SHW} \uparrow$ and $\mathrm{LW} \downarrow$ ) are taken directly from corrected observations. The turbulent fluxes SHF and LHF are calculated using the 'bulk' method, in which the fluxprofile relations are vertically integrated between the surface and the AWS measurement level. We use the stability functions proposed by Holtslag and de Bruin (1988) for stable conditions, and Dyer (1974) for unstable conditions. The surface roughness length for momentum $\left(z_{0, v}\right)$ was derived from on-site eddy-correlation measurements near AWS $6\left(z_{0, V}=0.16 \mathrm{~mm}\right)$ (Van den Broeke and others, 2004b) and near AWS $9\left(z_{0, V}=0.021 \mathrm{~mm}\right)$ (Van As and others, 2005). For AWS 5, which has a similar climate to AWS 6, we used $0.16 \mathrm{~mm}$; for AWS 4 we used $z_{0, v}=0.1 \mathrm{~mm}$ in line with values reported from the nearby ice-shelf stations Halley and Neumayer (Heinemann, 1988; King and Anderson, 1994). The temporal variation of $z_{0, v}$ is at present unknown and we assume it to be constant in time. For the calculation of the scalar roughness lengths for heat and moisture, we applied the expressions of Andreas (1987). 

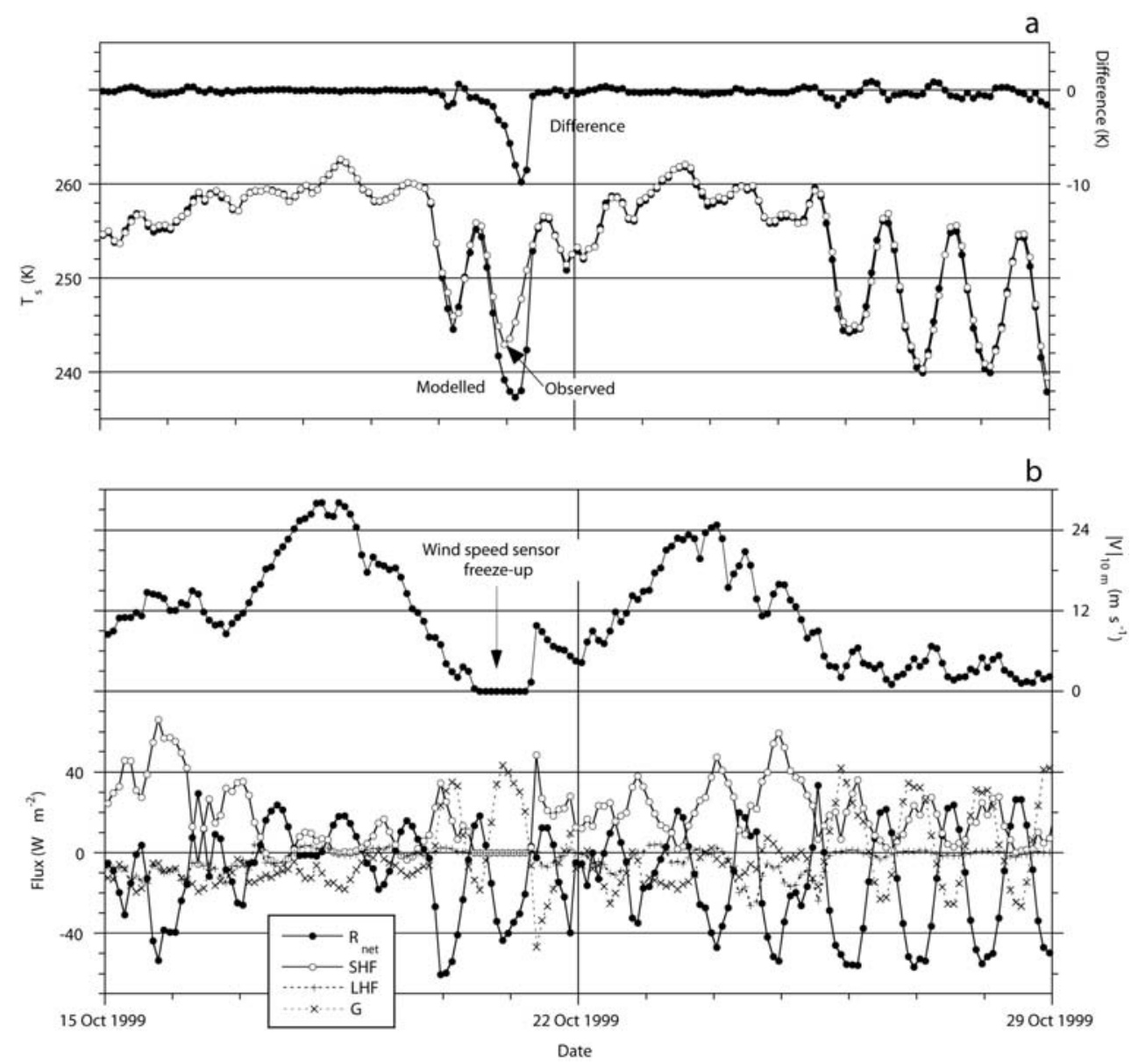

Fig. 4. (a) Modelled and observed surface temperature (left axis) and the difference (right axis) for a 2 week period in October 1999. (b) Observed $10 \mathrm{~m}$ wind speed (right axis) and modelled SEB components (left axis).

Heat conduction in the snow is calculated by solving the one-dimensional heat-transfer equation on grid levels spaced $0.04 \mathrm{~m}$ apart down to $20 \mathrm{~m}$ depth, below which heat conduction is assumed to vanish. The thermal conductivity of snow is assumed a function of snow density according to Anderson (1976). The conductive heat flux at the surface, $G$, is extrapolated upwards from its subsurface values at 2 and $6 \mathrm{~cm}$ depth. The full solving procedure of the SEB model is now as follows:

Initialize the model with measured snow temperatures, snow density and $z_{0, v}$;

Obtain SEB model input by linear interpolation of AWS data in time (AWS data are available every 2 hours, but the model time-step is $3 \mathrm{~min}$ );

Set $M=0$, cast SHF, LHF, $G$ and $\mathrm{LW} \uparrow$ in a form with $T_{\mathrm{s}}$ as the only unknown and solve the equation $\mathrm{SEB}=0$ for $T_{\mathrm{s}}$ by bisection in a $20 \mathrm{~K}$ search space, assuming neutral stability;

Iterate the calculations of the stability functions and $T_{\mathrm{s}}$ until $T_{\mathrm{s}}$ is stable within $0.01 \mathrm{~K}$;

If $T_{\mathrm{s}}>273.15 \mathrm{~K}$, it is set to $273.15 \mathrm{~K}$ and excess energy is used for melting. Meltwater is allowed to penetrate and refreeze in the snowpack;

Update the subsurface temperature field and proceed to the next time-step.

\section{RESULTS}

\subsection{Model validation}

Figure 3 shows a direct comparison of modelled and 'observed' $T_{\mathrm{s}}$ (using measured LW $\uparrow$ and assuming the surface to have unit emissivity). Each point represents a 2 hour average for the period 1998-2001 (4 years). Periods where the LW $\uparrow$ sensor was iced at AWSs 4 and 9 are excluded. The agreement is reasonable at AWS 9, with a root-mean-square difference (RMSD) of $1.8 \mathrm{~K}$. This represents an uncertainty in the SEB of $5 \mathrm{~W} \mathrm{~m}^{-2}$, using $\mathrm{d}\left(\varepsilon \sigma T^{4}\right) / \mathrm{d} t=4 \varepsilon \sigma T^{3}$. The RMSD is $<1 \mathrm{~K}$ at AWSs 4 and 5 and only $0.6 \mathrm{~K}$ at AWS $6\left(2 \mathrm{~W} \mathrm{~m}^{-2}\right)$. Another validation method for the SEB model is to compare modelled and observed subsurface snow temperatures (not shown). This shows excellent agreement at AWSs 5 and 6 (differences typically $<1 \mathrm{~K}$ ), and differences up to several $\mathrm{K}$ at AWSs 4 and 9 due to weaker winds and larger instrumental uncertainties at these sites.

The SEB model performs better in the katabatic wind zone, where icing seldom occurs because strong vertical mixing and adiabatic compression keep the relative humidity low (Table 2). Moreover, vertical mixing limits the static stability and therewith the dependence on the choice of stability functions which are similar at moderate stabilities (Andreas, 2002). Figure 4 gives an example of the accuracy of the SEB model in reproducing $T_{\mathrm{s}}$ at AWS 6 under a variety of weather conditions. We chose a 2 week period in October 1999, characterized by two high-wind-speed 

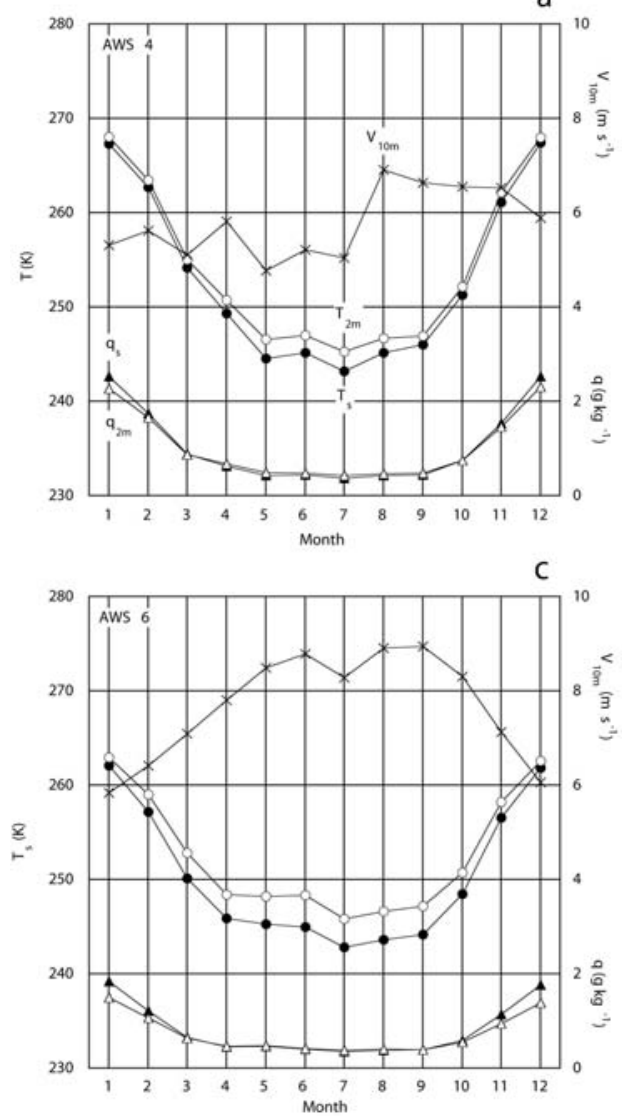

b
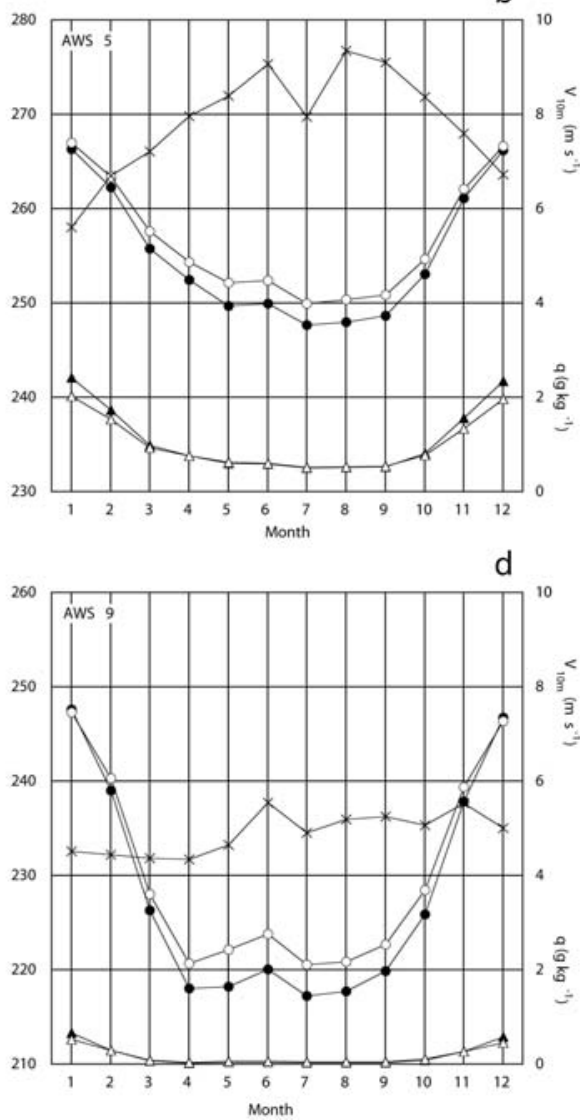

Fig. 5. Average seasonal cycle, 1998-2001, based on monthly means, of temperature ( $2 \mathrm{~m}$ and surface values; left axis), $10 \mathrm{~m}$ wind speed (right axis) and specific humidity (2 m and surface values; right axis) for (a) AWS 4, (b) AWS 5, (c) AWS 6 and (d) AWS 9.

events followed by a period of clear weather and weak winds. Temperatures ranged between 240 and $263 \mathrm{~K}$ (Fig. 4a). At this time of year, the sun is above the horizon for 18 hours each day, with a noontime top-of-atmosphere irradiance larger than $600 \mathrm{~W} \mathrm{~m}^{-2}$. Before the first storm, wind speeds are moderately high, but, judging from strong nocturnal radiative cooling, clear skies prevail. Under these conditions, nighttime SHF peaks at $70 \mathrm{~W} \mathrm{~m}^{-2}$, and significant sublimation (negative LHF) occurs in daytime. During the first event, the skies are overcast, as is evident from small nocturnal radiative cooling. As a result, stratification is near-neutral and SHF and LHF are small in spite of the strong wind. During the second event, clear skies again prevail, with large absolute values of SHF and LHF. When wind speed decreases after the event, $G$ and SHF become equally important in compensating nighttime radiative heat loss, while in daytime $G$ replaces LHF as the primary surface heat loss.

The SEB model reproduces measured $T_{\mathrm{s}}$ generally within $2 \mathrm{~K}$ (Fig. 4a), except for the period between the two storms, when the difference is $4-10 \mathrm{~K}$, the largest value found at this AWS during the 4 year period under consideration (Fig. 3c). The obvious reason is a frozen wind-speed sensor (Fig. 4b). When wind speed becomes zero, so does SHF, and an unrealistic modelled surface cooling occurs. This example demonstrates how sensor malfunctioning can directly and strongly affect modelled SEB components. Loss of sensor accuracy at low temperatures may also explain the relatively large scatter found at AWS 9 (Fig. 3d).

\subsection{Seasonal cycle of temperature, wind and specific humidity}

Figure 5 presents the seasonal cycle of temperature (left axis), specific humidity and wind speed (right axis), based on monthly means. The largest and smallest amplitudes in seasonality of $T_{2 \mathrm{~m}}$ are found at AWS $9(27 \mathrm{~K})$ and AWS 6 $(17 \mathrm{~K})$, respectively. At all AWSs, near-surface stratification is stable throughout the year $\left(T_{2 m}>T_{\mathrm{s}}\right)$, with the exception of December and January at AWS 9. In the stably stratified surface layer, wind shear is needed for the generation of turbulence. The weaker near-surface winds at AWSs 4 and 9 and the smoother surface at these sites inhibit vertical mixing and allow a stronger temperature inversion to develop near the surface, which explains the deeper wintertime temperature minimum compared to the katabatic wind zone. The wintertime wind-speed maximum at AWSs 5 and 6 supports the assumption that the winds are katabatic. A similar maximum cannot be found at AWSs 4 and 9; here, the near-surface wind is forced mainly by the large-scale pressure gradient, with modest monthly mean wind speeds of $4-7 \mathrm{~m} \mathrm{~s}^{-1}$ year-round. Given that relative humidity is relatively constant throughout the year (Van den Broeke and others, 2004a), specific humidity $q$ mostly reacts to changes in absolute temperature, and decreases from the coast towards the interior; the annual cycle in $q$ is largest at AWS 4 and smallest at AWS 9.

\subsection{Seasonal cycle of the SEB}

Annual mean values of the SEB components are listed in Table 2 (lower part), and the seasonal cycle (based on 
a
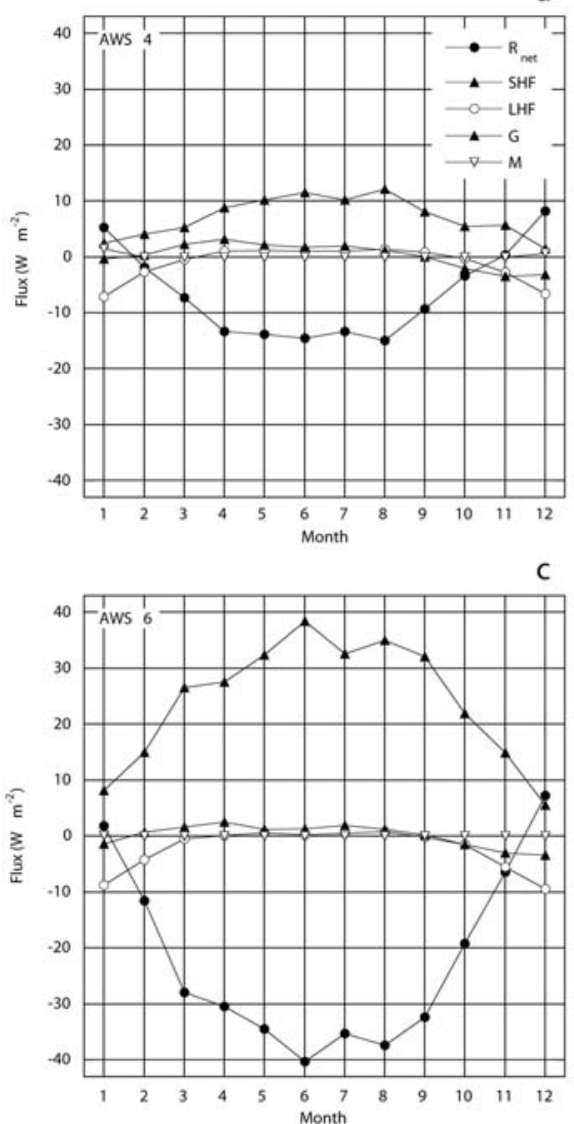

b

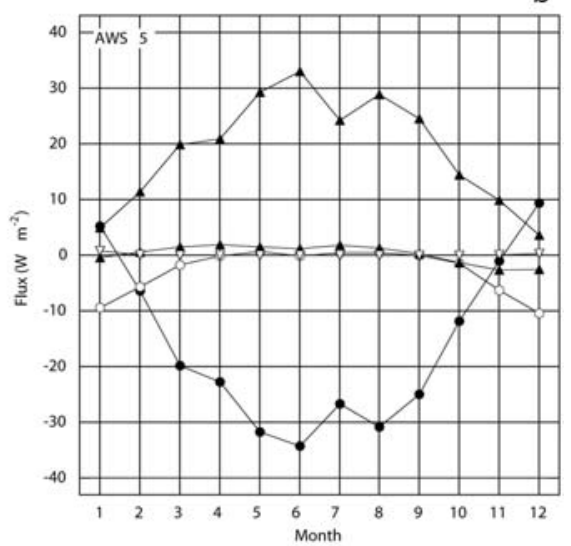

d

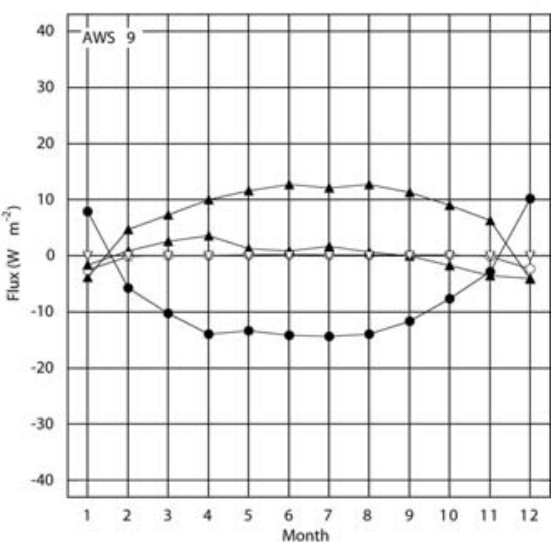

Fig. 6. Average seasonal cycle, 1998-2001, based on monthly means, of SEB components for (a) AWS 4, (b) AWS 5, (c) AWS 6 and (d) AWS 9.

monthly means) is presented in Figure 6. For easy reference, the monthly means have also been listed separately in Table 3. To highlight SEB gradients along the AWS sites, Figure 7 shows coast-to-interior profiles of the SEB components averaged for conditions representative for midsummer (December-January) and mid-winter (June-July). From Table 2 it is clear that the annual mean SEB mainly reflects winter conditions, when $R_{\text {net }}$ and SHF approximately balance. Assuming SHF vanishes at the top of the atmospheric boundary layer, this implies quasi-continuous cooling of the lower Antarctic atmosphere. Figure 6 shows that this cooling is much more effective in the katabatic wind zone (AWSs 5 and 6) than elsewhere, peaking in winter with remarkably large monthly mean SHF values of $20-40 \mathrm{~W} \mathrm{~m}^{-2}$ (Figs $6 \mathrm{~b}$ and $\mathrm{c}$ and $7 \mathrm{c}$ ). This can be ascribed to the strong positive feedback between surface cooling and near-surface wind speed in the katabatic wind zone. Note the similarity between the seasonal cycles of wind speed and SHF (Figs 5 and 6), stressing the importance of wind-shear-generated turbulence in the stable Antarctic surface layer. At AWSs 4 and 9, where katabatic forcing is weak or absent, strong wind events are associated with synoptic activity and overcast conditions. Under overcast conditions, $R_{\text {net }}$ is close to zero so that the surface layer thermal stratification is nearneutral, and turbulent heat exchange small, in spite of the strong wind. Consequently, wintertime SHF at AWSs 4 and 9 is only 9-12 $\mathrm{W} \mathrm{m}^{-2}$ (Fig. 7c).

The magnitude of monthly mean $G$ does not exceed $4 \mathrm{~W} \mathrm{~m}^{-2}$, with a maximum around April and a minimum around December at all AWSs (Figs 6 and 7), these being the months with the strongest temperature gradients in the nearsurface snowpack. However small, the contribution of $G$ to the SEB cannot be neglected; at AWS 9 in April, for instance, $G$ contributes $30 \%$ of the energy transport towards the surface and removes $50 \%$ of the energy from the surface in November and December. Similar values apply to AWS 4. Deposition of moisture is a small source of heat during winter at all AWSs. Only at AWS 4 does it exceed $1 \mathrm{~W} \mathrm{~m}^{-2}$ during winter, comprising $<10 \%$ of the heat transport towards the surface.

The SEB is very different during the brief summer, when a significant amount of shortwave radiation is absorbed at the snow surface. At the same time, $\mathrm{LW}_{\text {net }}$ becomes more strongly negative in response to a sharp increase in surface temperature (cf. Fig. 7a and c). As a result, $R_{\text {net }}$ becomes only slightly positive in December and January (Figs 6 and 7), with values between $4 \mathrm{Wm}^{-2}$ (AWS 6) and $9 \mathrm{Wm}^{-2}$ (AWS 9), where clouds are least frequent and optically thin. There is an abrupt transition from stable to unstable conditions between AWSs 6 and 9 (Fig. 7b). A negative monthly mean SHF implies that daytime cooling of the surface by convection is larger than nighttime heating of the surface by a downward-directed sensible heat transport. The explanation for the relatively strong convection on the plateau is two-fold: first, nocturnal slope flows in the katabatic wind zone generate large positive SHF that keeps the daily and monthly mean SHF positive. Second, the most important daytime heat sink at the lower sites is sublimation, with summertime mean values of -7 to $-10 \mathrm{~W} \mathrm{~m}^{-2}$ (Fig. 7b). On the plateau, however, low temperatures limit sublimation 
Table 3. Monthly mean energy-balance components (1998-2001) (units are $\mathrm{W} \mathrm{m}^{-2}$ )

\begin{tabular}{|c|c|c|c|c|c|}
\hline & $\mathrm{SHW}_{\text {net }}$ & $\mathrm{LW}_{\text {net }}$ & SHF & LHF & G \\
\hline \multicolumn{6}{|l|}{ AWS 4} \\
\hline January & 43 & -38 & 2 & -7 & 0 \\
\hline February & 26 & -28 & 4 & -3 & 0 \\
\hline March & 13 & -20 & 5 & 0 & 2 \\
\hline April & 2 & -15 & 9 & 1 & 3 \\
\hline May & 0 & -14 & 10 & 1 & 2 \\
\hline June & 0 & -14 & 12 & 1 & 2 \\
\hline July & 0 & -13 & 10 & 1 & 2 \\
\hline August & 1 & -16 & 12 & 1 & 1 \\
\hline September & 8 & -18 & 8 & 1 & 0 \\
\hline October & 17 & -20 & 5 & 0 & -2 \\
\hline November & 33 & -32 & 6 & -3 & -3 \\
\hline December & 42 & -34 & 2 & -7 & -3 \\
\hline \multicolumn{6}{|l|}{ AWS 5} \\
\hline January & 53 & -48 & 5 & -9 & 0 \\
\hline February & 35 & -41 & 11 & -6 & 1 \\
\hline March & 17 & -37 & 20 & -2 & 1 \\
\hline April & 2 & -25 & 20 & 0 & 2 \\
\hline May & 0 & -32 & 29 & 1 & 3 \\
\hline June & 0 & -34 & 33 & 0 & 1 \\
\hline July & 0 & -27 & 24 & 1 & 3 \\
\hline August & 1 & -32 & 29 & 0 & 1 \\
\hline September & 11 & -35 & 25 & 0 & 0 \\
\hline October & 26 & -38 & 14 & -1 & -1 \\
\hline November & 48 & -49 & 10 & -6 & -3 \\
\hline December & 56 & -47 & 4 & -10 & -3 \\
\hline \multicolumn{6}{|l|}{ AWS 6} \\
\hline January & 60 & -58 & 8 & -9 & -1 \\
\hline February & 37 & -49 & 15 & -4 & 1 \\
\hline March & 16 & -44 & 27 & -1 & 2 \\
\hline April & 2 & -32 & 28 & 0 & 3 \\
\hline May & 0 & -34 & 32 & 1 & 1 \\
\hline June & 0 & -40 & 38 & 0 & 1 \\
\hline July & 0 & -35 & 33 & 0 & 2 \\
\hline August & 1 & -38 & 35 & 1 & 1 \\
\hline September & 8 & -40 & 32 & 0 & 0 \\
\hline October & 27 & -46 & 22 & -1 & -1 \\
\hline November & 52 & -58 & 15 & -6 & -3 \\
\hline December & 62 & -54 & 6 & -9 & -3 \\
\hline \multicolumn{6}{|l|}{ AWS 9} \\
\hline January & 68 & -60 & -4 & -3 & -2 \\
\hline February & 32 & -37 & 5 & 0 & 1 \\
\hline March & 15 & -25 & 7 & 0 & 3 \\
\hline April & 2 & -16 & 10 & 0 & 4 \\
\hline May & 0 & -13 & 12 & 0 & 1 \\
\hline June & 0 & -14 & 13 & 0 & 1 \\
\hline July & 0 & -14 & 12 & 0 & 2 \\
\hline August & 0 & -14 & 13 & 0 & 1 \\
\hline September & 8 & -20 & 11 & 0 & 0 \\
\hline October & 25 & -32 & 9 & 0 & -2 \\
\hline November & 48 & -50 & 6 & 0 & -4 \\
\hline December & 73 & -63 & -4 & -2 & -4 \\
\hline
\end{tabular}

(Fig. 5d); in the absence of other significant heat sinks, surface temperatures can rise rapidly in daytime causing significant convection. The daily development of a shallow $(\approx 100 \mathrm{~m})$ but well-defined daytime mixed layer on the Antarctic Plateau has been confirmed by SODAR (sonic detection and ranging) measurements at Dome C (Mastrantonio and others, 1999) and tethered balloon soundings at Kohnen base (Van As and others, 2005).
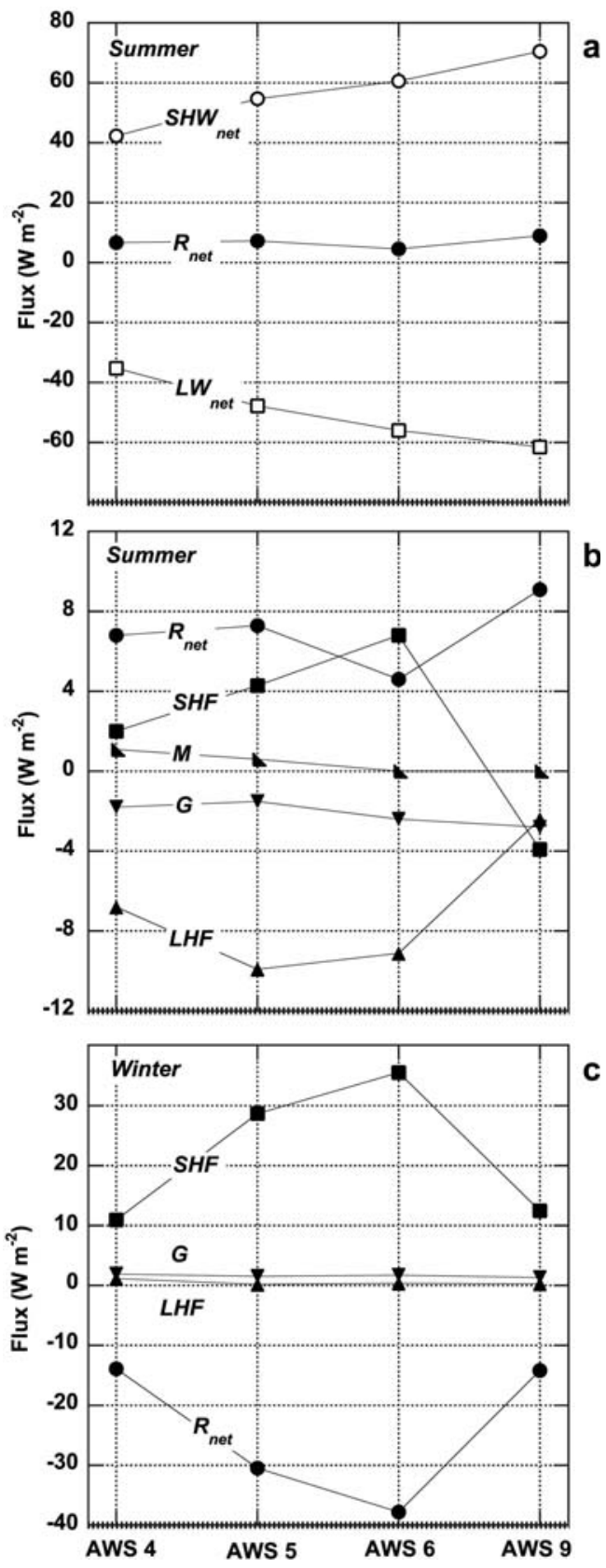

Fig. 7. Horizontal profiles along the AWS of seasonally averaged SEB components for the period 1998-2001. Summer is average of December and January; winter is average of June and July. (a) Summer radiation budget; (b) summer energy budget; and (c) winter energy budget.

At AWSs 4-6, the contribution of melt becomes non-zero in December and January, but it remains a relatively small component of the SEB (Figs 6 and 7). For the summer mass balance, however, melting constitutes a significant negative contribution at AWSs 4 and 5 (Van den Broeke and others, 2005).

\section{CONCLUSIONS}

We calculated the seasonal cycle of the Antarctic SEB using 4 years of extensively quality-controlled AWS data. The four AWSs used in this study are situated on the coastal ice shelf, in the coastal and inland katabatic wind zone and in the interior plateau of Dronning Maud Land. Calculated and 
observed 2 hourly mean surface temperatures have a RMSD $<2 \mathrm{~K}$ for the plateau AWS (corresponding to an uncertainty in the SEB of $\left.5 \mathrm{~W} \mathrm{~m}^{-2}\right)$ and $<1 \mathrm{~K}\left(3 \mathrm{~W} \mathrm{~m}^{-2}\right)$ for the other AWSs.

At all AWSs the annual mean net radiation is negative, resulting in a stably stratified surface layer. This requires wind shear to generate turbulent heat exchange, so that differences in the seasonal cycle of the SEB can be explained largely in terms of differences in wind climate. In the katabatic wind zone, the combination of clear skies and strong winds generates a large downward turbulent flux of sensible heat, which is especially large $\left(20-40 \mathrm{~W} \mathrm{~m}^{-2}\right)$ in winter. On the coastal ice shelf and the interior plateau, episodes with strong winds are associated with overcast conditions, limiting sensible heat transport to around $10 \mathrm{~W} \mathrm{~m}^{-2}$.

During the short Antarctic summer (December and January), net radiation becomes slightly positive. At the low-elevation AWSs, sublimation of snow from the surface is the main compensating heat loss. On the high plateau, even in summer, temperatures are too low for significant sublimation to occur; as a result, surface temperatures rise quickly in daytime, causing convection to be the main surface heat sink in the Antarctic interior.

\section{ACKNOWLEDGEMENTS}

We thank C. Genthon, G. Krinner, J. Box and A. Monaghan for carefully reviewing the manuscript. Numerous colleagues at Institute for Marine and Atmospheric Research Utrecht and abroad are thanked for AWS support. This work is partly funded by the Netherlands Antarctic Programme (NAAP) and the Netherlands Organization of Scientific Research, Earth and Life Sciences section (NWO/ALW). This work is a contribution to the 'European Project for Ice Coring in Antarctica' (EPICA), a joint European Science Foundation (ESF)/European Commission (EC) scientific programme, funded by the EC and by national contributions from Belgium, Denmark, France, Germany, Italy, the Netherlands, Norway, Sweden, Switzerland and the United Kingdom. This is EPICA publication No. 110.

\section{REFERENCES}

Anderson, E.A. 1976. A point energy and mass balance model of a snow cover. NOAA Tech. Rep. NWS-19.

Anderson, P.S. 1994. A method for rescaling humidity sensors at temperatures well below freezing. J. Atmos. Ocean. Tech., 11(5), 1388-1391.

Andreas, E.L. 1987. A theory for the scalar roughness and the scalar transfer coefficients over snow and sea ice. Boundary-Layer Meteorol., 38(1-2), 159-184.

Andreas, E.L. 2002. Parameterizing scalar transfer over snow and ice: a review. J. Hydrometeorol., 3(4), 417-432.

Bintanja, R. 2000. The surface heat budget of Antarctic snow and blue ice: interpretation of temporal and spatial variability. J. Geophys. Res., 105(D19), 24,387-24,407.

Bintanja, R. and M.R. van den Broeke. 1995. The surface energy balance of Antarctic snow and blue ice. J. Appl. Meteorol. 34(4), 902-926.

Bintanja, R., S. Jonsson and W.H. Knap. 1997. The annual cycle of the surface energy balance of Antarctic blue ice. J. Geophys. Res., 102(D2), 1867-1881.
Brandt, R.E. and S.G. Warren. 1993. Solar-heating rates and temperature profiles in Antarctic snow and ice. J. Glaciol., 39(131), 99-110.

Carroll, J.J. 1982. Long-term means and short-term variability of the surface energy balance components at the South Pole. J. Geophys. Res., 87(C6), 4277-4286.

Clow, G.D., C.P. McKay, G.M. Simmons, Jr and R.A. Wharton, Jr. 1988. Climatological observations and predicted sublimation rates at Lake Hoare, Antarctica. J. Climate, 1(7), 715-728.

Dyer, A.J. 1974. A review of flux-profile relationships. BoundaryLayer Meteorol., 7, 363-372.

Heinemann, G. 1988. On the structure and energy budget of the boundary layer in the vicinity of the Filchner/Ronne ice shelf front (Antarctica). Beiträge zur Physik der Atmosphäre, 61(3), 244-258.

Heinemann, G. and L. Rose. 1990. Surface energy balance, parameterizations of boundary-layer heights and the application of resistance laws near an Antarctic ice shelf front. BoundaryLayer Meteorol., 51(1-2), 123-158.

Holtslag, A.A.M. and H.A.R. de Bruin. 1988. Applied modeling of the nighttime surface energy balance over land. J. Appl. Meteorol., 27(6), 689-704.

King, J.C. and P.S. Anderson. 1994. Heat and water vapour fluxes and scalar roughness lengths over an Antarctic ice shelf. Boundary-Layer Meteorol., 69(1-2), 101-121.

King, J.C., P.S. Anderson, M.C. Smith and S.D. Mobbs. 1996. The surface energy and mass balance at Halley, Antarctica during winter. J. Geophys. Res., 101(D14), 19,119-19,128.

Liljequist, G.H. 1957. Energy exchange of an Antarctic snow-field: surface inversions and turbulent heat transfer (Maudheim $\left.71^{\circ} 03^{\prime} \mathrm{S}, 10^{\circ} 56^{\prime} \mathrm{W}\right)$. Norwegian-British-Swedish Antarctic Expedition, 1949-52, Sci. Results, 2(1D).

Mastrantonio, G., V. Malvestuto, S. Argentini, T. Georgiadis and A. Viola. 1999. Evidence of a convective boundary layer developing on the Antarctic Plateau during the summer. Meteorol. Atmos. Phys., 71(1-2), 127-132.

Ohata, T., N. Ishikawa, S. Kobayashi and S. Kawaguchi. 1985. Heat balance at the snow surface in a katabatic wind zone, East Antarctica. Ann. Glaciol., 6, 174-177.

Reijmer, C.H. and J. Oerlemans. 2002. Temporal and spatial variability of the surface energy balance in Dronning Maud Land, East Antarctica. J. Geophys. Res., 107(D24), 4759-4770.

Renfrew, I.A. and P.S. Anderson. 2002. The surface climatology of an ordinary katabatic wind regime in Coats Lane, Antarctica. Tellus, 54A, 464-484.

Stearns, C.R. and G.A. Weidner. 1993. Sensible and latent heat flux estimates in Antarctica. In Bromwich, D.H. and C.R. Stearns, eds. Antarctic meteorology and climatology: studies based on automatic weather stations. Washington, DC, American Geophysical Union, 109-138.

Van As, D., M.R. van den Broeke and R.S.W. van de Wal. 2005. Daily cycle of the surface energy balance on the high Antarctic plateau. Antarct. Sci., 17(1), 121-133.

Van den Broeke, M.R., D. van As, C. Reijmer and R. van de Wal. 2004a. Assessing and improving the quality of unattended radiation observations in Antarctica. J. Atmos. Ocean. Tech., 21(9), 1417-1431.

Van den Broeke, M.R., D. van As, C.H. Reijmer and R.S.W. van de Wal. 2004b. The surface radiation balance in Antarctica as measured with automatic weather stations. J. Geophys. Res., 109(D9), D09103. (10.1029/2003JD004394.)

Van den Broeke, M.R., C.H. Reijmer and R. van de Wal. 2005. A study of the Antarctic mass balance using automatic weather stations. J. Glaciol., 50(171), 565-583.

Wendler, G., N. Ishikawa and Y. Kodama. 1988. The heat balance of the icy slope of Adélie Land, eastern Antarctica. J. Appl. Meteorol., 27(1), 52-65. 